\title{
The 2017 Best STEM Books (Resource Exchange)
}

\section{Dr. Pamela S. Lottero-Perdue, Towson University}

Pamela S. Lottero-Perdue, Ph.D., is Associate Professor of Science Education in the Department of Physics, Astronomy \& Geosciences at Towson University. She has a bachelor's degree in mechanical engineering, worked briefly as a process engineer, and taught high school physics and pre-engineering. She has taught engineering and science to children in multiple informal settings. As a pre-service teacher educator, she includes engineering in her elementary and early childhood science methods courses, and has developed engineering education courses for middle school pre-service teachers and practicing elementary teachers. She has provided science and engineering professional development to multiple schools and school systems in Maryland, and has significantly contributed to the writing of many integrated STEM units of instruction used by teachers and school systems. Her research has examined factors that support and those that hinder elementary teachers as they learn to teach engineering, and currently focuses on how children learn to engineer and in the process, learn to fail and productively persist. She is the Director of the Integrated STEM Instructional Leadership (PreK-6) Post-Baccalaureate Certificate Program at TU. She currently serves as the Chair of the Pre-College Engineering Education Division of ASEE, and is a member of the ASEE Board of Directors Committee on P12 Engineering Education. 


\section{The 2017 Best STEM Books for K12 Students}

Presented at the 2017 American Society for Engineering Education (ASEE) Annual Conference \& Exposition, Pre-College Engineering Education (PCEE) Division Resource Exchange

Presenter: Dr. Pamela Lottero-Perdue, Associate Professor, Department of Physics, Astronomy \& Geosciences, Towson University \& Chair, PCEE Division, ASEE; plottero@,towson.edu

Background: Between July and November 2016, nine individuals - including the presenter each reviewed over 250 books published after 2014 to determine the first ever "Best STEM Books" list for kindergarten through high school readers. Reviewers were representatives from the following participating organizations:

- ASEE,

- The International Technology and Engineering Educators Association (ITEEA),

- The National Science Teachers Association (NSTA),

- The Society of Elementary Presidential Awardees (SEPA), and

- The Children's Book Council (CBC).

The books reach K12 audiences, and thus, are valuable teaching tools for K12 educators, librarians, out-of-school educators, and parents.

Selection Criteria: A separate team of educators developed the initial set of criteria for 2017 book selection. Those criteria were updated and can be found in full in the article, "Best STEM Books" (NSTA, 2017). Best STEM Books need to address one STEM field, and must invite "STEM-like thinking." Much of this thinking overlaps with habits of mind and practices within engineering design. The best STEM trade books invite STEM-like thinking by:

- Modeling real-world innovation

- Embracing real-world design, invention and innovation

- Connecting with authentic experiences

- Showing assimilation of new ideas

- Illustrating teamwork, diverse skills, creativity and cooperation

- Inviting divergent thinking and doing

- Integrating interdisciplinary and creative approaches

- Exploring multiple solutions to problems
- Addressing connections between STEM disciplines

- Exploring Engineering Habits of Mind

○ Systems thinking

- Creativity

- Optimization

- Collaboration

- Communication

- Ethical Considerations

- Critical Thinking

NSTA. (2017) Best STEM Books. Science and Children, 54(6), 71-78.

For More Information: Download the "Best STEM Books" article for free from the NSTA website by going to http://www.nsta.org/publications/, and selecting the February 2017 issue of Science and Children, Science Scope, or The Science Teacher. This article includes an annotated list of all 31 books on the list, additional criteria related to science and engineering practices, a list of all reviewers, and the call for submissions for the 2018 Best STEM Books. See also http://static.nsta.org/pdfs/2017BestSTEMBooks.pdf for a list of all 31 books and review criteria. 
2017 Best STEM Books in alphabetical order by title. (Title. Authors / Illustrators. Publisher. Age Range.)

1. Ada Byron Lovelace and the Thinking Machine. Wallmark / Chu. Creston Books. K-5.

2. Ada's Ideas: The Story of Ada Lovelace, the World's First Computer Programmer. Robinson. Abrams. 1-5.

3. Ada Lovelace, Poet of Science: The First Computer Programmer. Stanley / Hartland. Paula Wiseman Books.

4. Ben Franklin's Big Splash: The Mostly True Story of His First Invention. Rosenstock / Schindler. Calkins Creek. 3-5.

5. Breakthrough: How One Teen Innovator is Changing the World. Andrake. Harpercollins. 9-12.

6. Emmet's Storm. Rubino. Catree Books. 4-8.

7. Fearless Flyer: Ruth Law and her Flying Machine. Lang / Colón. Calkins Creek. K-3.

8. Genetic Engineering: Science, Technology and Engineering. Burgan. Scholastic. 5-8.

9. A Global Warming Primer: Answering Your Questions About the Science, the Consequences and the Solutions. Bennett. Big Kid Science. 6-12.

10. Green City: How One Community Survived a Tornado and Rebuilt for a Sustainable Future. Drummand. Macmillan/Farrar Straus Giroux. K-3.

11. Hello Ruby: Adventures in Coding. Liukas. MacMillan/Feiwel \& Friends. K-3.

12. Inventions that Could Have Changed the World, but Didn't. Rhatigan / Owsley. Charlesbridge. 3-7.

13. The Inventor's Secret. Slade / Reinhard. Charlesbridge. 1-4.

14. The Marvelous Thing that Came from a Spring: The Accidental Invention of the Toy that Swept the Nation. Ford. Simon \& Schuster/Atheneum Books for Young Readers. K-3.

15. The Most Magnificent Thing. Spires. Kids Can Press. K-2.

16. Red Madness: How a Medical Mystery Changed What We Eat. Jarrow. Calkins Creek. 5-12.

17. Sabotage: The Mission to Destroy Hitler's Atomic Bomb. Bascomb. Arthur A. Levine books. 7-12.

18. The Secret Subway. Corey / Red Nose Studio. Random House Children's Books, Schwartz \& Wade. $\mathrm{K}-3$.

19. Six Dots: A Story of Young Louis Braille. Bryant / Kulikov. Random House Children's Books. Alfred A. Knopf. K-2.

20. Solving the Puzzle Under the Sea: Marie Tharpe Maps the Ocean Floor. Burleigh / Colón. Simon \& Schuster/Paula Wiseman Books. K-3.

21. Steve Jobs: Insanely Great. Hartland. Random House Children's Books, Schwartz \& Wade. 7-12.

22. Super Gear: Nanotechnology and Sports Team Up. Swanson. Charlesbridge. 4-7.

23. Swap! Light. Candlewick Press. K-2.

24. Ticktock Benneker's Clock. Keller / Gardner. Sleeping Bear Press. K-2

25. Trailblazers: 33 Women in Science Who Changed the World. Swaby. Random House Children's Bks, Delacorte. 5-9.

26. Wangari Maathai: The Woman Who Planted Millions of Trees. Prévot / Fronty. Charlesbridge. 1-5.

27. Welcome to Mars. Aldrin and Dyson. National Geographic Kids Books. 3-7.

28. What Does It Mean to Be an Entrepreneur? DiOrio, Dryden / Min. Little Pickle Press. K-3.

29. Whoosh! Lonnie Johnson's Super-Soaking Stream of Inventions. Barton / Tate. Charlesbridge. 2-5.

30. Women of Stone and Steel. Lewis. Chicago Review Press. 7-12.

31. Women Who Launched the Computer Age. Calkhoen / Petersen. Simon \& Schuster/Simon Spotlight. $1-3$. 